\title{
Lei de Informática e seus Resultados no Polo de Informática de Ilhéus, BA
}

\author{
Computer Law and its Results in Ilhéus Computer Pole, BA
}

\author{
Rafaele Paz Comin ${ }^{1}$ \\ Marcelo Cezar Carvalho Borges ${ }^{1}$ \\ Marilís Pereira Moura ${ }^{1}$ \\ Silvio Luis Comin ${ }^{1}$ \\ Gesil Sampaio Amarante Segundo ${ }^{1}$ \\ Marina Oliveira Lucas Tavares ${ }^{1}$ \\ ${ }^{1}$ Universidade Estadual de Santa Cruz - UESC, Ilhéus, BA, Brasil
}

\begin{abstract}
Resumo
O presente artigo aborda a efetividade de políticas públicas de ciência, tecnologia e inovação a partir de levantamento e análise da Lei de Informática em um polo industrial relacionado a um setor considerado prioritário. Neste trabalho realizou-se uma pesquisa exploratória como forma de pesquisa bibliográfica que possibilitou uma abordagem da inovação sob a perspectiva da regulamentação e do financiamento governamental, aferindo-se o papel do governo nesse processo e analisando-se o resultado da Lei de Informática nas empresas instaladas no Polo de Informática de Ilhéus - BA. Conclui-se que políticas públicas de incentivos, se não aliadas a outras ações, não são suficientes. Não há desenvolvimento regional sem ações coordenadas pelas diversas esferas do poder público que possam garantir que as empresas tenham todas as condições para o seu crescimento.
\end{abstract}

Palavras-chave: Políticas públicas de incentivo à inovação. Lei de Informática. Pesquisa e Desenvolvimento

\begin{abstract}
This article discusses the effectiveness of public policies on science, technology and innovation based on the survey and analysis of the Information Technology Law in an industrial area related to a priority sector. The work carried out an exploratory research as a form of bibliographical research enabling an approach of innovation from the perspective of regulation and government financing, assessing the role of the government in this process and analyzing the result of the Information Technology Law in the companies installed in the Information Technology Center of Ilhéus - BA. It is concluded that public incentive policies, if not allied to other actions, are not enough. There is no regional development without coordinated actions by the various spheres of government that can ensure that companies have all the conditions for their growth.
\end{abstract}

Keywords: Public policies to encourage innovation. Information Technology Law. Research and Development Área tecnológica: Inovação Tecnológica 


\section{Introdução}

O desenvolvimento tecnológico de um país passa diretamente pela utilização intensiva da ciência e tecnologia e pela inovação tecnológica. O Brasil precisa aumentar seus esforços para construir um modelo de desenvolvimento tecnológico consistente com sua importância para o desenvolvimento econômico e social. Para alcançar esse objetivo, necessita de políticas de incentivo à inovação que estimulem a utilização de conhecimento adquirido ou gerado localmente para a criação ou melhora de produtos, processos e serviços.

Nesse contexto, novas estratégias e políticas de fomento à inovação também vêm sendo estabelecidas no Brasil, enquanto outras mais antigas vêm sendo atualizadas. No final dos anos 1990, a criação dos fundos setoriais teve como objetivo captar outras fontes de financiamento para Ciência e Tecnologia (C\&T) no Brasil e estimular a interação entre empresas, universidades e centros de pesquisa. A partir dos anos 2000, o governo brasileiro incorporou outros instrumentos de incentivo ao esforço inovativo das empresas - Lei da Inovação (Lei ${ }^{\circ}$ 10.973/2004); Lei do Bem (Lei n 11.196/2005); além da continuidade da já existente Lei da Informática (Leis n 8.248/1991 e n 10.176/2001). Dessa forma, o Brasil procurou estabelecer lin has gerais de incentivo e financiamento à pesquisa tecnológica e ao desenvolvimento da inovação tecnológica (GOMES; FORNARI; PINHO, 2015 apud MCTI, 2013; HOLLANDA, 2010; DE NEGRI et al., 2009; RAPINI, 2009; PUGA, 1999), incluindo nessa relação a Lei Rouanet da Pesquisa (Lei $n^{\circ}$ 11.487/07): regulamentada em novembro de 2007, que modifica a Lei do Bem ao incluir a redução fiscal para empresas que atuarem em parcerias com instituições científicas e tecnológicas (ICTs); e a Lei de informática (Lei $\mathrm{n}^{\circ} 11.077 / 04$, que alterou as Leis $n^{\circ}$ 10.664/03, 10.176/01 e 8.248/91), que exige o cumprimento de um conjunto mínimo de operações a serem realizadas no país (O processo Produtivo Básico ou PPB), o investimento da empresa em pesquisa e desenvolvimento (P\&D), cria um incentivo extra para as regiões Norte, Nordeste e Centro-Oeste e define a redução de IPI até 2019.

As políticas públicas para a inovação são fundamentais em todas as fases do desenvolvimento tecnológico, e ainda mais relevantes nas etapas de pesquisa e na busca de inovações radicais. Essas políticas, destinadas a estimular a inovação industrial, se orientadas para a redução dos custos com atividades de $\mathrm{P} \& \mathrm{D}$, podem incorporar mecanismos para o financiamento direto às empresas ou por meio de incentivos fiscais que reduzam compensatoriamente a carga tributária sobre as empresas (FREEMAN, 1995).

O objetivo deste artigo é abordar a efetividade de políticas públicas de ciência, tecnologia e inovação a partir de levantamento e análise da Lei de Informática no Polo de Informática de Ilhéus, BA, através de uma pesquisa exploratória e bibliográfica

\section{Revisão de Literatura}

\subsection{O conceito de "Inovação"}

O estudo dos empreendimentos inovadores se inicia no entendimento do conceito de inovação. Tidd, Bessant e Pavitt (2008) atribuem a Joseph A. Schumpeter, em sua obra de 1939, 
a origem do termo inovação. Inovar é oriundo do latim innovare, que quer dizer tornar novo, sendo então inovação o ato de inovar. Esses autores consideram Schumpeter o pioneiro e mais influente autor nos estudos de inovação.

Os primeiros modelos conceituais sobre inovação concebiam que esta era originada apenas pelas necessidades do mercado, sendo impulsionadas pela tecnologia ou pela busca de soluções de problemas existentes no mercado.

Com base na teoria de Schumpeter (1961), da "destruição criativa" ou "destruição criadora", para qual dedicou um capítulo do seu livro, ele defende que inovação é a capacidade da empresa de superar a concorrência por meio da criação do novo em substituição ao que já existe e está sendo copiado, portanto se tornando obsoleto por meio da difusão tecnológica. Há uma constante busca pela criação de algo novo, tudo sendo orientado pela busca de novas fontes de lucratividade (SCHUMPETER, 1982).

Segundo Smith (1997), considerando uma forma de visão onde a concorrência implica no surgimento de diversidade no sistema econômico e as mudanças ocorridas ao longo do tempo advém de vários tipos de inovações, provoca-se um fenômeno sistêmico no qual o processo de inovação em geral é desenvolvido e sustentado por uma ligação inter-firma e por uma complexa rede de relações interinstitucionais.

Assim, a inovação é a realização de novas combinações que tragam retorno financeiro às empresas no mercado competitivo. Inovar, pragmaticamente, é transformar ideias novas em resultados sustentáveis, ou seja, consiste no justo equilíbrio entre criatividade e processo de geração de valor. Nesta teoria, Schumpeter explica que os resultados benéficos da exploração de uma inovação são temporários, pois a inovação pode ser copiada pelos demais capitalistas atraídos pela oportunidade de aumentar seus lucros e para manter a sua fatia no mercado, perdendo o seu diferencial inovativo e estimulando a constante introdução de inovações para recomeço de um novo ciclo e impulsionamento do desenvolvimento econômico (SCHUMPETER, 1984).

Entretanto, apesar do consenso quanto à importância de se inovar no processo competitivo, não existe uma unanimidade quanto ao seu real significado (CASSIOLATO; LASTRES, 2005). O conceito de inovação muito se modificou, principalmente com novos estudos desenvolvidos pelos neo-schumpeterianos, tais como Kim e Richard Nelson. Ambos definem que a inovação é "uma atividade precursora, originalmente enraizada nas competências internas da empresa, para desenvolver e introduzir um novo produto no mercado pela primeira vez" (KIM; NELSON, 2005, p. 16).

Segundo Gomes et al. (2015), as políticas para inovação são essenciais em todas as fases dos desenvolvimentos tecnológicos, mais especificamente na fase da pesquisa básica ou pura e das inovações radicais.

As políticas destinadas ao apoio à inovação, se bem orientadas para redução dos custos relativos e dos riscos associados à $\mathrm{P} \& \mathrm{D}$, podem agregar importantes mecanismos para financiamento direto às empresas via transferências financeiras a fundo perdido, financiamentos a taxa de juros inferior a de mercado etc., ou por meio de incentivos fiscais que reduzam a carga tributária sobre as empresas (FREEMAN, 1995).

O Brasil ganhou expressão industrial tardiamente. De fato, a industrialização ocorreu essencialmente na segunda metade do século XX. Paralelamente, a nossa academia também tomou corpo de forma tardia, uma vez que não se tem universidades centenárias (algumas resultaram da agregação de instituições temáticas isoladas, como escolas de medicina ou de direito), e 
mesmo após suas criações, a maioria permaneceu por longo tempo com cunho fortemente educacional, sendo a pesquisa brasileira muito jovem.

Salerno e Kubota (2008) observaram que a partir dos anos 1970 a pós-graduação ganhou impulso, beneficiada pela inserção de políticas de bolsas para mestrado e doutorado no exterior para a formação dos pesquisadores. Dessa forma, seguindo os preceitos de modelo linear, o Brasil investiu tardiamente, começando pela ciência - criação da pós-graduação com apoio do Conselho Nacional de Desenvolvimento Científico e Tecnológico (CNPq), da FINEP e da Coordenação de Aperfeiçoamento de Pessoal de Nível Superior (Capes); e por mecanismos de financiamento competitivo para a pesquisa científica nas universidades e nos institutos de pesquisas $(\mathrm{CNPq}$, FINEP, Fundações de Amparo à Pesquisa). Porém, mesmo com os arcabouços supracitados, não criou, simultaneamente, um sistema robusto de financiamento e de indução do desenvolvimento tecnológico e da inovação na empresa, que essencialmente replicava tecnologias importadas.

Nos anos de 1950, empresas estrangeiras foram atraídas para explorar o mercado brasileiro, e dessa forma a inovação genuinamente brasileira não era prioridade da política pública no período posterior à segunda Guerra Mundial.

Nos anos seguintes, 1960 a 1970, os mercados continuavam fechados, as taxas de importação continuavam altas e não facilitavam o projeto local do produto. Dessa forma, até o fim dos anos 1980, a economia inibia a competição internacional em um momento crucial de transformação da base produtiva (Tecnologia de Informação e Comunicação - TICs: computadores, softwares e microeletrônica).

Ainda citando Salerno e Kubota (2008), no início dos anos 1980, ainda sobre o marco regulatório de um mercado fechado, Lei do Similar Nacional, entre outras, nasceu a Lei de Informática, porém sem foco e infrutífera, pois apenas reservava o mercado para produções locais de todo bem de informática. No Governo Collor, a Lei do Similar Nacional foi revogada, alterando substancialmente o marco regulatório. As tarifas para importação foram baixadas, assim como várias restrições para importações deixaram de existir, dando um choque de competitividade na indústria brasileira. Já no final dos anos 1980, no Governo Sarney, foram desenvolvidos instrumentos de incentivos fiscais à $\mathrm{P} \& \mathrm{D}$ nas empresas que possibilitaram a criação do Programa de Desenvolvimento Tecnológico Industrial (PDTI). Nos anos 1990, já no segundo Governo de Fernando Henrique, o MCT criou fundos setoriais para financiamentos à pesquisa; e no Governo Luís Inácio Lula da Silva o novo arcabouço legal, com a Lei da Inovação e a Lei do Bem, possibilitou ao Estado o financiamento direto de P\&D nas empresas.

Todos esses entraves que fazem parte da inovação no Brasil corroboram para o posicionamento do Brasil frente a outros países de bases tecnológicas. Para Pacheco (2010), o desenvolvimento da ciência e tecnologia está alicerçado em premissas consideradas fundamentais, como: a criatividade humana e o incentivo ao seu potencial; a mobilidade da sociedade ou país em busca de objetivos e metas capazes de trazer benefícios; e o esforço governamental que possibilita o investimento necessário para a área de C\&T (VIOTTI; BAESSA; KOELLER, 2005).

Em 2002 o MCT lançou o "Livro Branco" com o objetivo de apontar caminhos para que a ciência Tecnologia e Inovação (CT\&I) pudessem contribuir para a construção de um país mais dinâmico, competitivo e socialmente mais justo.

A referida obra justifica: 
A análise da sociedade e da economia internacionais indica que as nações mais bem-sucedidas são as que investem, de forma sistemática, em Ciência e Tecnologia e são capazes de transformar os frutos desses esforços em inovações. Um dos resultados mais evidentes desses investimentos é a capacidade que essas nações têm de propiciar alta qualidade de vida, empregos bem remunerados, segurança pública e seguridade social a seus cidadãos. Seus bens e serviços caracterizam-se por serem tecnologicamente avançados, ou seja, por incorporarem de forma intensiva o conhecimento. A produção e a comercialização de tais bens e serviços refletem o maior potencial que esses países dispõem de geração de renda e crescimento econômico, em função seja do próprio valor agregado a esses produtos, seja do grande dinamismo de seus mercados (MCTI, 2002, p. 23).

Conforme descrito anteriormente, a inovação era vista como um processo linear, que teve início na pesquisa básica, seguiu para a aplicada e, depois, partiu para a introdução, no mercado, de novos produtos. Esse processo linear foi denominado como primeira geração. A segunda geração é identificada com os Sistemas Nacionais de Inovação (SNI), e nesse sentido, a OCDE (2005), recomendou que o papel governamental não se restringisse apenas ao papel tecnológico. Já na terceira geração, a mesma propõs uma ação mais integrada das políticas voltadas à inovação.

O processo de inovação tem características sistêmicas e é condicionado por políticas, por um conjunto de instituições, públicas e privadas, e pela qualidade e intensidade de suas inter-relações (MCT, 2002).

E, por ter características sistêmicas, faz-se necessária a existência de uma regulação, coordenação exercida por instituições públicas ou privadas, objetivando a dinâmica desse processo. Pacheco (2010) resume que a ideia de Sistema Nacional de Inovação pode ser interpretada como um agente essencial para gerenciar e incentivar novos fluxos e canais de informação que transformam simples e isoladas empresas em verdadeiras unidades responsáveis pelo desenvolvimento econômico.

A política de Ciência e Tecnologia só se concretiza se a sua base de formulação estiver assentada na vontade política, tendo como sustentação um projeto nacional que defina o grau de dependência tecnológica desejada para a nação. O grau de dependência e de sofisticação da base técnica vai depender, na sua essência, da disposição dos segmentos de capitais em reivindicar e apoiar a Política de Ciência e Tecnologia, resultando o processo em que diferentes forças articulam-se no sentido de orientar, fornecer ou dificultar o movimento de criação e incorporação de novos conhecimentos científicos e tecnológicos ao sistema produtivo (CUNHA, 1982, p. 86 ).

Desse modo, as políticas públicas em Ciência e Tecnologia sofrem a influência de diversos autores responsáveis pela economia de um estado. O sistema Nacional de Inovação é reconhecido como uma importante "construção institucional resultante de uma ação planejada e consciente de um somatório de decisões não planejadas e desarticuladas que impulsiona o progresso tecnológico em economias capitalistas complexas" (ALBUQUERQUE, 1996).

Para Cassiolato e Lastres (2000), o sistema Nacional de Inovação é definido como "um conjunto de instituições distintas que conjuntamente e individualmente contribuem para o de- 
senvolvimento e difusão de tecnologia”. Os autores também citam que esse sistema é formado não só por empresas, mas também por instituições de ensino e pesquisa tecnológica, por agentes financiadores de crédito e pelo governo.

É válido citar que o SNI determina o nível e a direção do desenvolvimento tecnológico, dando volume e compondo o processo gerador de mudanças em um país, porém não significa que um país que detenha um alto grau de pesquisa apresente uma elevada taxa de desenvolvimento técnico eficiente das instituições. Para que ocorra a elevação das taxas de desenvolvimento é preciso ter um sistema de pesquisas muito bem direcionado, organizado e, acima de tudo, devidamente gerenciado em nível nacional (NELSON, 1993).

\subsection{Breve Descrição do Polo de Informática de Ilhéus}

Visando à interiorização da indústria baiana e à revitalização da economia do município de Ilhéus e seu entorno, como resultado do planejamento estadual, nasceu em 19 de junho de 1995, através do Decreto Estadual n 4.316/95, o Polo de Informática e Eletroeletrônicos de Ilhéus (PII), concentrado, a princípio, na área do Distrito Industrial desta cidade.

O objetivo era reativar a economia regional, seriamente atacada por conta da queda da cultura do cacau, grande economia na região até então. Rapidamente transformou-se no principal polo gerador de empregos e renda da região, e contribuiu para que a cidade deixasse de ser conhecida apenas como terra do cacau, difundida mundialmente pelas obras do escritor Jorge Amado. A sua localização visava atender à necessidade de encontrar uma vertente industrial que pudesse trazer para llhéus um substitutivo à altura, que minimizasse o enorme vazio na economia local deixado pela crise da lavoura cacaueira, em decorrência da "vassoura de bruxa", que assolava os cacauais, dizimando a produtividade e causando desemprego em toda região. O decreto $n^{\circ} 4.316 / 95$ trouxe um importante diferencial competitivo para as empresas que se instalassem no distrito industrial de Ilhéus, mas trouxe também algumas distorções. Inicialmente, em sua interpretação, dava brechas para que empresas se instalassem fora de Ilhéus, conseguindo os mesmos benefícios que as empresas que aqui se instalassem. Foram assim perdidos alguns importantes empreendimentos, como a Semp Toshiba e outras indústrias relevantes, que receberam os mesmos incentivos para se localizarem em Salvador. Porém, logo a distorção foi corrigida, e atingiram-se números extremamente significativos no PII.

A isenção e/ou redução de carga tributária estadual, aliada aos benefícios da Lei no 8.248/91 - conhecida como Lei de Informática -, e à localização estratégica, na entrada do Nordeste, trouxe um importante desenvolvimento para a região.

Em 1998, foi criado o SINEC - Sindicato das Indústrias de Aparelhos Elétricos, Eletrônicos, Computadores, Informática e Similares dos Municípios de Ilhéus e Itabuna -, uma ação de união das empresas que aqui se instalavam para buscar melhorias que pudessem beneficiar toda a região.

Ilhéus entrou no mapa da Tecnologia no Brasil. Seus resultados eram claros e atraíam empresas do Brasil e do exterior, interessadas em fazer negócios com as indústrias aqui instaladas. Com base no relatório de avaliação elaborado pelo Governo da Bahia no ano de 1999, nos primeiros 5 anos de implantação do Polo, existiam 12 empresas atuando nesse segmento, sendo a maior parte constituída de empresas de pequeno porte. 
Apesar dos problemas estruturais, o Polo apresentou uma tendência crescente desde o início de sua implantação, e o número de empresas aqui instaladas foi sendo elevado, saltando de um faturamento anual da ordem de aproximadamente $\mathrm{R} \$ 700$ milhões em 2001 para $\mathrm{R} \$ 2,5$ bilhões em 2007. Foram instaladas mais de 70 empresas, chegando a responder por aproximadamente $25 \%$ da produção nacional de microcomputadores. No ano de 2007 foram contabilizados mais de 5.000 empregos diretos e indiretos, crescimento significativo em relação às 12 empresas instaladas até o ano de 1999. O Polo de Informática de Ilhéus estava completamente consolidado. No ano de 2008, iniciou-se um período de queda, resultado da crise econômica mundial e das deficiências ainda não resolvidas. As indústrias locais sofreram o impacto, visto que são dependentes, em sua maioria, de importação de partes e peças para sua produção.

Aliado ao período de crise que se iniciava, outras regiões do País começaram a oferecer benefícios similares aos previstos no Decreto Estadual, melhor infraestrutura e logística. Perdendo competitividade e com a continuidade dos problemas estruturais do PII, as empresas começaram a deixar o município de Ilhéus para se instalar em outros polos de tecnologia. Atualmente, 20 empresas operam no PII.

O ambiente acadêmico local, essencialmente a Universidade Estadual de Santa Cruz (UESC), embora em franco desenvolvimento, não estava ainda suficientemente madura nas áreas de interesse do Polo (havia já em 2002 um bacharelado em Ciência da Computação mais Engenharia de Produção, mas as Engenharias Elétrica, Mecânica e Química foram criadas apenas após 2010) e a instituição sofria de deficiências burocráticas que dificultavam as parcerias - a Lei Federal de Inovação não se aplicava às instituições estaduais e a Lei Estadual, de dezembro de 2008, nunca foi regulamentada. O campus do Instituto Federal da Bahia implementado em Ilhéus, por decisão de sua reitoria, e a despeito do resultado de audiências públicas, ignorou a existência do Polo na definição de seus cursos. Porto e aeroporto local sofrem de deficiências que nunca foram devidamente atacadas. Os serviços de conectividade e fornecimento de energia são também de qualidade inferior ao necessário para um polo industrial competitivo.

A consolidação do CEPEDI, da UESC e de suas pós-graduações em ciências exatas, a criação da Universidade Federal do Sul da Bahia, do Parque Científico e Tecnológico do Sul da Bahia e do Instituto Senai de Tecnologia em Ilhéus trazem expectativas de melhorias na vertente do ambiente acadêmico, se aliado às soluções para os demais problemas.

\section{Metodologia}

Esta pesquisa foi desenvolvida como uma pesquisa exploratória que tem como principal objetivo proporcionar ao pesquisador uma maior familiaridade com o problema em estudo (GIL, 2008). Procurou-se conhecer as políticas públicas existentes de apoio às atividades inovativas e de desenvolvimento tecnológico. Como técnica para explorar o tema de pesquisa foi realizado o levantamento bibliográfico em artigos e livros de referência e a pesquisa documental, buscando uma abordagem da inovação sob a perspectiva da regulamentação $e$ do financiamento governamental, aferindo-se o papel do governo nesse processo e analisando-se os resultados da Lei de Informática nas empresas instaladas no Polo de Informática de Ilhéus - BA. Através do método escolhido, foi possível realizar um levantamento de documentos e fazer a análise de dados primários e secundários que legitimam os aspectos investigados, como por exemplo, 
relatórios cedidos pelo Sindicato das Indústrias de Aparelhos Elétricos, Eletrônicos, Computadores, Informática e Similares dos Municípios de Ilhéus e Itabuna - SINEC, Centro Tecnológico Regional Sul do Serviço Nacional de Aprendizagem Industrial - CT Sul - SENAI e Centro de Pesquisa e Desenvolvimento em Informática e Eletroeletrônico de Ilhéus - CEPEDI.

\section{Resultados e Discussão}

Historicamente, o Brasil vem implementando políticas mais sistemáticas de apoio à inovação, e, mais especialmente, vem objetivando engajar as empresas em estratégias de inovação de produtos, de processos, de formas de uso, de distribuição, de comercialização etc., visando a atingir, dessa forma, um patamar superior de desenvolvimento e de geração de renda. A Política Industrial, Tecnológica e de Comércio Exterior (PITCE), lançada em novembro de 2003, e o Plano de Desenvolvimento da Produção, em maio de 2008, colocam a inovação como fator fundamental para que a indústria brasileira dê um salto de qualidade rumo à diferenciação de produtos, transformando, assim, sua própria estrutura industrial. Em 2007, o Brasil voltou a crescer mais vigorosamente e o investimento na economia aumentou.

De acordo com Salerno e Kubota (2008), o Brasil foi construindo, ao longo dos 25 anos, um sistema mais completo de inovação. As construções iniciais foram associadas à implantação da pós-graduação, passando pela criação de fundos especiais para o financiamento da pesquisa, entre outras ações. Uma mudança de qualidade ocorreu em 2005, com a disponibilização de um conjunto inédito de instrumentos de apoio à inovação nas empresas, bem como de algumas instituições para ajudar nesse movimento.

O País passou a contar, então, com lei de incentivo fiscal à P\&D nas empresas, semelhante às leis dos principais países do mundo com destaque em inovação, e, em alguns casos, melhor e mais eficiente, pois era de adoção automática, sem exigências burocráticas, como no caso dos incentivos fiscais previstos na Lei do Bem; com a possibilidade de subvenção a projetos de empresas considerados importantes para o desenvolvimento tecnológico; com subsídio para a fixação de pesquisadores nas empresas; com programas de financiamento à inovação; com programas de capital empreendedor; e com arcabouço legal mais propício para a interação universidade/empresa.

No Brasil, 45,7\% do investimento em P\&D é feito pelas empresas, enquanto em vários outros países com economias mais caracterizadas por produtos intensivos em tecnologia essa proporção chega próximo a $70 \%$, o que demonstra que a participação do setor privado nos esforços tecnológicos ainda está aquém dos níveis observados internacionalmente (MCTI, 2012).

A Lei de Informática $n^{\circ} 8.248 / 91$ teve vigência em 1993, quando pôs fim às restrições anteriores ao capital estrangeiro, que caracterizaram a década de $80 \mathrm{com}$ sua reserva de mercado para empresas nacionais que desenvolvessem atividades de informática. Tal mudança protecionista proposta na Lei foi resultado das pressões comerciais internacionais e nacionais, que não aceitavam mais o mecanismo regulatório restritivo.

A Lei de Informática concede incentivos fiscais para empresas produtoras de bens de informática, automação e telecomunicação. As empresas beneficiadas recebem um abatimento de até $80 \%$ do Imposto sobre Produtos Industrializados (IPI) sobre produtos de harware. Tal redução exige uma contrapartida de investimento em PD\&I de $5 \%$ do faturamento anual de 
produtos incentivados, descontados os impostos de comercialização (COFINS, PIS, ICMS e IPI). O benefício para as regiões Norte e Nordeste é de $95 \%$ da redução de IPI para produtos de informática em geral e de $100 \%$ de redução para microcomputadores e partes, e peças em geral. Os benefícios estimulam a instalação de plantas fabris, a contratação de recursos humanos e o aumento da produção de bens de informática para consumo no mercado brasileiro.

As empresas beneficiadas da Lei de Informática devem apresentar, anualmente, o Relatório Demonstrativos Anual - RDA, que prova o cumprimento das obrigações estabelecidas pelo Decreto $n^{\circ} 5.906 / 06$.

Até o momento não existe estudos específicos que mensurem o efetivo retorno da Lei de Informática, porém o MCTI, baseado nos RDA's enviados pelas empresas beneficiadas, disponibilizou alguns dados.

No Brasil, conforme mostra o gráfico da Figura 1, o número de empresas beneficiadas pela Lei de Informática saltou de 262 empresas no ano de 2006 para 510 no ano de 2014 . O MCTI recentemente atualizou esses dados, e esse número já ultrapassa 600 empresas em 2018.

Figura 1 - Número de Empresas Participantes

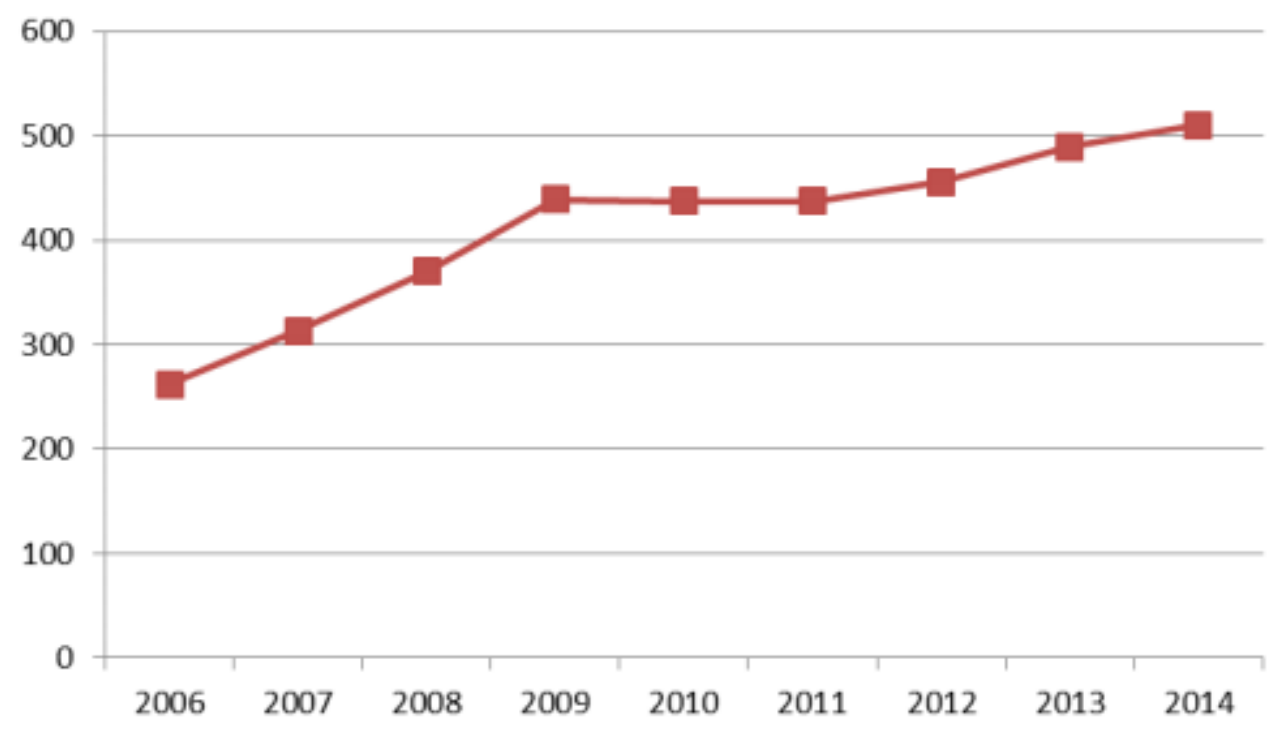

Fonte: MCTI (2015)

O governo federal utiliza esse mecanismo para estimular a competitividade e a capacitação técnica da indústria. Atualmente, 300 universidades e institutos recebem recursos para fazer pesquisas na área de tecnologia.

A contrapartida de investimento em PD\&I pode ser realizada através de Projetos Próprios, Projetos Conveniados via Centro de Tecnologia devidamente credenciado ao Comitê da área de Tecnologia da Informação (CATI), Depósitos no Fundo Nacional de Desenvolvimento Científico e Tecnológico (FNDCT) e Programas Prioritários.

O gráfico da Figura 2 mostra a distribuição das obrigações de aplicação em P\&D. 
Figura 2 - Distribuição de Aplicação em P\&D

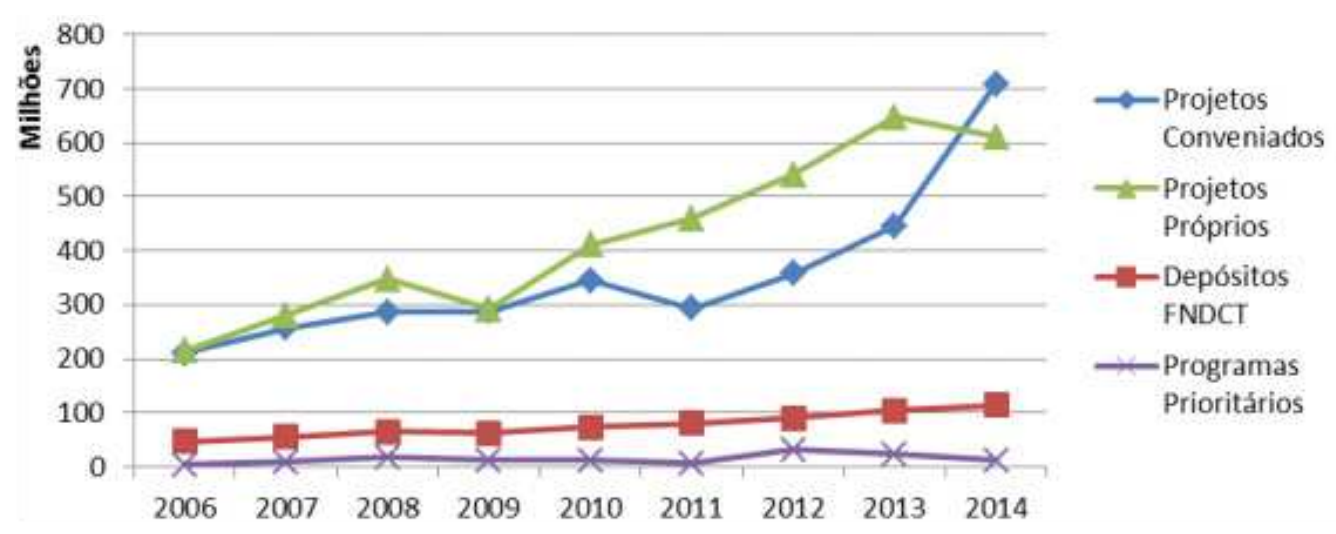

Fonte: MCTI (2015)

No ano de 2006 foram realizados 214 projetos próprios dentro das empresas beneficiadas e em 2014 esse número subiu para 611. É necessário ressaltar que uma empresa pode realizar mais de um projeto, desde que o valor total atinja o montante total da sua obrigação em investimento em P\&D no ano base.

Em 2006 as empresas realizaram 211 projetos conveniados com institutos credenciados pelo CATI. A empresa também é obrigada a dividir esse percentual com institutos públicos e privados, o que, inevitavelmente, estimula a interação entre a universidade e a empresa. Esse número saltou para 709 projetos no ano de 2014.

Com a modernização da Lei de Informática através da MP n 810/2017, convertida em Lei $\mathrm{n}^{\circ}$ 13.674, de 12 de junho de 2018, tornou-se possível que as empresas apliquem a contrapartida em fundos de investimentos destinados à capitalização de empresas de bases tecnológicas, as Startups. Esse modelo, de investimento de contrapartida, deve promover um grande avanço no incentivo a pequenos negócios voltados à inovação.

Observa-se na Figura 3 um aumento nos projetos que geraram patentes. Esses projetos podem ter sido realizados dentro da empresa ou em parceria com institutos e universidades, o que leva a concluir que o incentivo contribui com a pesquisa e sobretudo com o processo de desenvolvimento para a competitividade do país.

Figura 3 - Patentes e Publicações

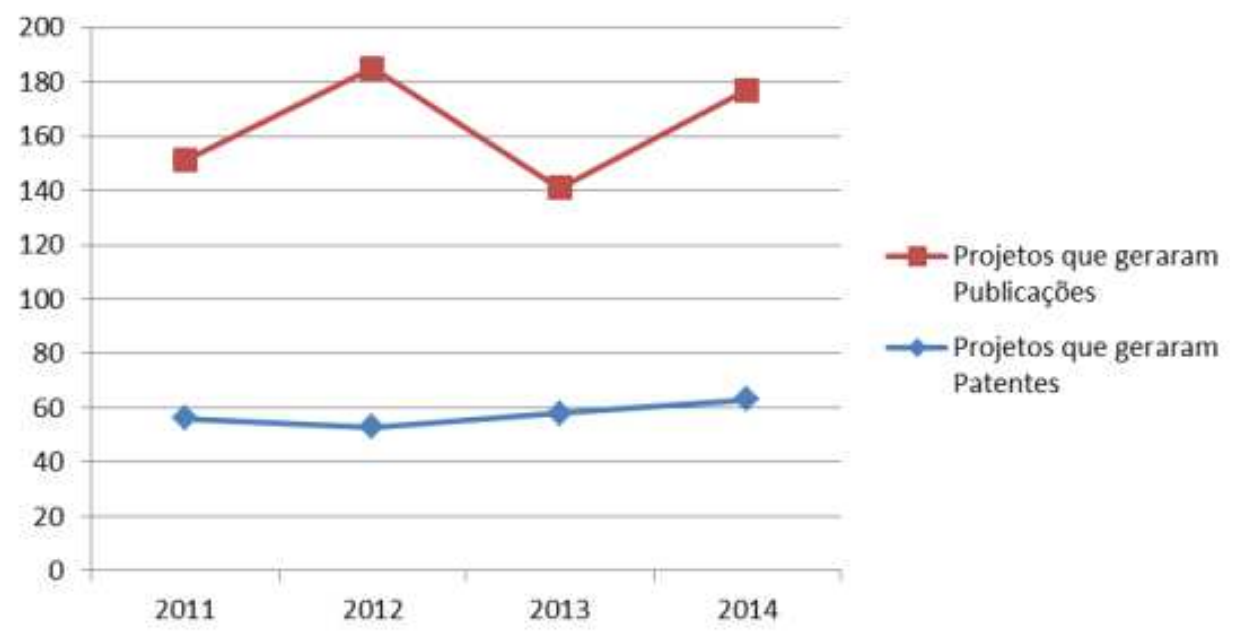

Fonte: MCTI (2015) 
No polo de informática de Ilhéus, BA, objeto de estudo do presente artigo, além de beneficiarem-se dos incentivos oriundos da Lei de Informática, as empresas instaladas no polo também contam com o Decreto Estadual $n^{\circ} 4.316 / 95$. Os benefícios principais contidos no decreto são resumidos no diferimento do pagamento do ICMS para operações de industrialização de empresas instaladas no Distrito Industrial de Ilhéus, bem como na redução da carga tributária para saídas internas de produtos acabados recebidos do exterior, até a alíquota de 3,5\%. Tais incentivos movimentaram muito a região, com a atração de inúmeras empresas e investimentos, conforme já descritos e detalhados nos tópicos anteriores. Os incentivos federais do Processo Produtivo Básico (PPB), aliados aos incentivos locais, tornaram Ilhéus uma importante opção para implantação de empresas de tecnologia.

A cidade conta com a Universidade Estadual de Santa Cruz (UESC), com o CEPEDI e o CT Sul - SENAI, sendo todos credenciados junto ao CATI.

O gráfico da Figura 4 mostra os valores de projetos desenvolvidos em parceria com os ICTs locais e a quantidade de empresas de Ilhéus, entre os anos de 2011 a 2016.

Figura 4 - Empresa e Valores de Projetos Desenvolvidos

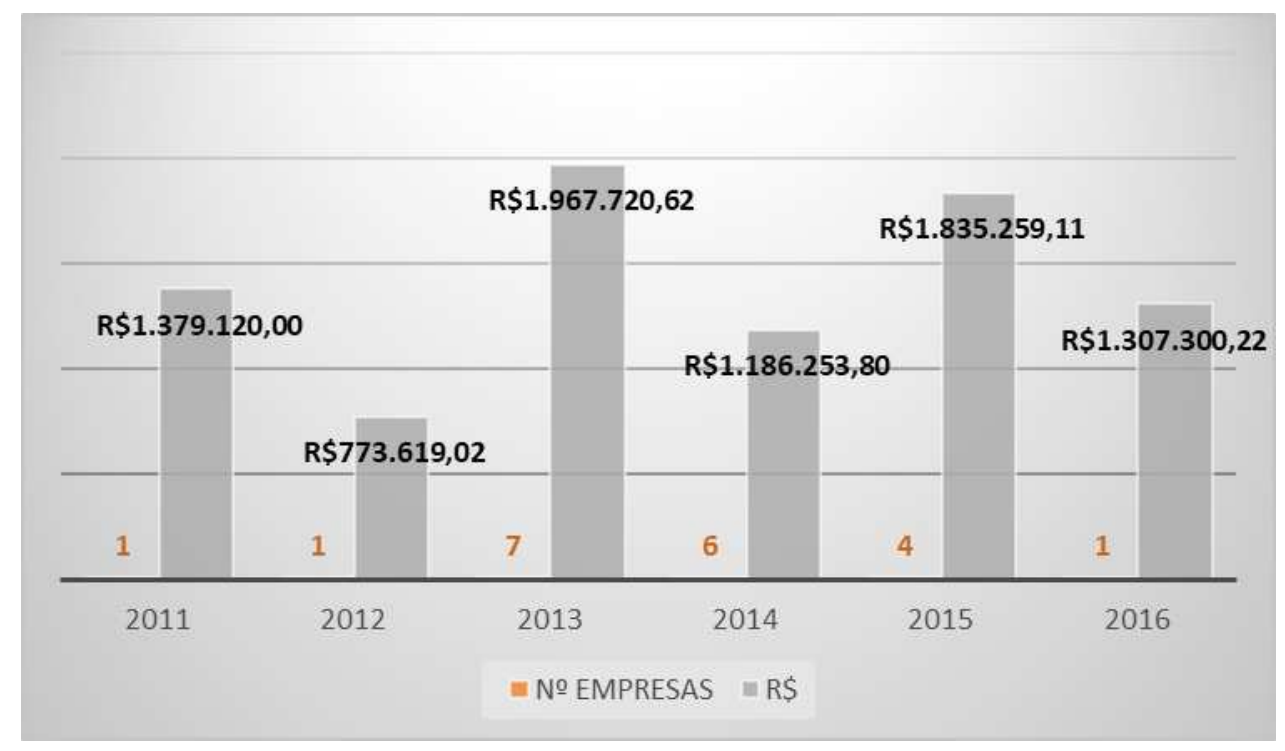

Fonte: MCTI (2015)

Observa-se, a partir do gráfico, uma oscilação tanto no valor investido quanto na quantidade de empresas que investiram em P\&D entre os anos de 2011 a 2016 . A variação de número de empresas investindo em institutos locais tem dois grandes motivadores:

a) As empresas locais têm investido a maior parte de seus recursos em institutos localizados em outras unidades da federação, o que demonstra uma fragilidade do arranjo local em não fortalecer os institutos locais.

b) As empresas, por conta da retração do mercado, não têm atingido o faturamento bruto que as obrigue a fazer investimentos em parceria com ICTs, limitando-se a investir os poucos recursos em projetos próprios, normalmente com pequeno potencial inovador.

A criação do polo de informática de Ilhéus foi, comprovadamente, um importante fator de crescimento para a região, trazendo inúmeros benefícios, como o desenvolvimento tecnológico e o fortalecimento da economia local, chegando a gerar mais de 5.000 empregos diretos e in- 
diretos. Porém, a falta de investimentos locais em infraestrutura básica, a competitividade com outras unidades da federação, aliada a crises econômicas locais e globais, fizeram com que o crescimento não fosse mantido. Esses acontecimentos inibiram a atração de novos investimentos para a região, além de fazer com que unidades já instaladas no Polo de Informática de Ilhéus deixassem a região. Aliado a isso, alguns estados da federação começaram a questionar os créditos de ICMS de operações provenientes do Decreto $n^{\circ} 4.316$ (a chamada guerra fiscal), o que tirou competitividade das empresas instaladas na região. Outras unidades da Federação lançaram políticas de incentivos similares às oferecidas em Ilhéus, aliadas a projetos de implantação e oferecimento de infraestrutura compatível com a necessidade das indústrias. Esses fatores fizeram com que houvesse uma queda vertiginosa nos resultados do Polo de Informática de Ilhéus, que, apesar de continuar sendo importante na economia local, está muito distante dos resultados alcançados no passado, e com poucas perspectivas de retomada de crescimento.

\section{Considerações Finais}

Historicamente, nossos ambientes mais inovadores crescem devido a uma necessidade em ter novas oportunidades de emprego e aumentar a renda, o que é muito frágil como ambiente inovador, pois as dificuldades são, facilmente, um motivo para desistência e também a primeira oportunidade de substituição por um emprego formal com carteira assinada pode ocasionar o abando do processo ou projeto inovador.

Essas características, associadas à falta de uma cultura de inovação como um processo fundamental para a sobrevivência do negócio ou do aumento do faturamento da empresa, são entraves que convivem com as políticas de inovação, que precisam evoluir ainda mais, mantendo o foco não apenas nos incentivos fiscais, mas premiando as empresas que se destacam com soluções inovadoras.

Fomento ao $\mathrm{P} \& \mathrm{D}$, aliado a políticas públicas de incentivos à implantação de novos empreendimentos, é um fator muito importante para o desenvolvimento de uma região. Isso aconteceu com o Polo de informática de Ilhéus, que foi de extrema importância para o desenvolvimento do município. Os incentivos implementados, porém, não foram suficientes para a manutenção do Polo de informática. Incentivos fiscais, se não aliados a outras políticas públicas para fortalecimento e atração de empresas, não são suficientes para o sucesso de uma região. Outras ações relacionadas à infraestrutura local, logística, segurança, criação local de empresas de base tecnológica, entre outras, têm importância fundamental para que as empresas tenham segurança econômica para fazer seus investimentos em uma região; e não têm seus benefícios restritos apenas ao setor, mas a toda atividade econômica, incluindo a indústria de alimentos, serviços, turismo, e ao desenvolvimento social local.

Não há desenvolvimento regional sem ações coordenadas pelo poder público, em todos os segmentos, que possam garantir que as empresas tenham todas as condições para seu crescimento. A competitividade entre os estados mostra que ações de incentivos fiscais, por si só, não são suficientes para o sucesso de um empreendimento como o Polo de Informática de Ilhéus.

Por fim, como sugestão de estudos futuros que possam superar uma limitação do presente artigo, recomenda-se que outros levantamentos sejam realizados, aferindo as diferentes formas de aplicação da contrapartida em P\&D, incorporando, inclusive, dados mais recentes fornecidos pelo MCTIC. 


\section{Referências}

ALBUQUERQUE, E.M. Sistema Nacional de Inovação no Brasil: uma análise introdutória a partir de dados disponíveis sobre a tecnologia. Revista de Economia Política, vol. 16, nº 3 (63), 1996.

ARCHIBUGI, D. Patenting as an indicator of technological innovation: a review. Science and Public Policy, p. 357-368, 1992.

BAESSA, A.R.; KOELLER, P.; VIOTTI, E. B. Inovações, Padrões Tecnológicos e Desempenhos das Firmas Industriais Brasileiras. IPEA, 2005.

BARDIN L. Análise de conteúdo. Lisboa: Edições 70, 1977.

BRASIL. Ministério da Ciência e tecnologia. Livro branco: ciência, tecnologia e inovação. Brasília: MCTI, 2002. p. 05-27.

CASSIOLATO, J. E.; LASTRES, H.M.M. Revista Parcerias Estratégicas, nº 8, maio 2000. Sistemas de inovação e desenvolvimento: as implicações de política. São Paulo

Perspectiva, v. 19, n.1, p. 34-45, jan./mar. 2005.

CUNHA, S. Padrões de intervenção do Estado em Ciência e Tecnologia. Revista de Economia, Curitiba: UFPR, n 16, 1992.

DE NEGRI, J. A,; DE NEGRI, F. Políticas de Incentivo à Inovação Tecnológica no Brasil. Brasília: IPEA, 2008. p 292.

DE NEGRI, F; DE NEGRI, J. A.; LEMOS, M. B. Impactos da ADTEN e do FNDCT sobre o Desempenho e os Esforços Tecnológicos das Firmas Industriais Brasileiras. Revista Brasileira da Inovação, Rio de Janeiro (RJ), v. 8, n. 1, p. 211-254, jan./jul. 2009.

ÉRBER, F. Desenvolvimento tecnológico e intervenção do estado. Revista de Administração Pública, Rio de Janeiro, v. 14, nº 04, 1980.

FREEMAN, C. The "National System of Innovation" in historical perspective. Cambridge Journal of Economics, n. 19, p. 5-24, 1995.

GIL, Antonio Carlos. Como elaborar projetos de pesquisa. 4. ed. São Paulo: Atlas, 2008.

GOMES, C. M.; KRUGLIANSKAS, I. Indicadores e Características da Gestão de Fontes Externas de Informação Tecnológica e do Desempenho Inovador de Empresas Brasileiras. RAC, v. 13, n. 2, p. 172-188, 2009.

GOMES, R.; FORNARI, V. C. B.; PINHO, G. Financiamento aos investimentos em Inovação e atividades Tecnológicas no Brasil e no Estado de São Paulo: Um estudo comparativo. ALTEC 2015.

HOLLANDA, F. S. M. Financiamento e incentivos à inovação industrial do Brasil.2010. Tese (Doutoramento em Economia). Campinas: Instituto de Economia; Universidade Estadual de Campinas, 2010.

KAYANO J.; CALDAS, E. de L. Indicadores para o Diálogo. Série Indicadores, n. 8, p. 1-11, 2002.

KIM, L.; NELSON, R.R. Tecnologia, aprendizado e inovação: as experiências das economias de industrialização recente. São Paulo: Editora UNICAMP, 2005. 
MATTOS, J. R. L.; GUIMARÃES, L.S. Gestão da tecnologia e Inovação. Uma abordagem Prática. São Paulo. Ed. Saraiva, 2005.

MCTI. Séries Históricas dos Resultados da Lei de Informática - Lei no 8.248/91: Dados dos Relatórios Demonstrativos de Anos Base 2006 a 2014 - Versão 1, 2018. Brasília: MCTI, 2018.

Relatório Anual da Utilização dos Incentivos Fiscais - Ano Base 2012 - Capítulo III da Lei do Bem - Lei No 11.196/2005. Brasília: MCTI, 2013

Estratégia Nacional de Ciência, Tecnologia e Inovação: balanço das atividades estruturantes 2011. Brasília: MCTI, 2012.

Relatório Anual de Dimensão Estratégica. Brasília: MCTI, 2002.

NELSON, R. R. National Innovation System. A comparative Analysis. Nova York: Oxford University Press, 1993.

ORGANIZAÇÃO PARA A COOPERAÇÃO E O DESENVOLVIMENTO ECONÔMICO (OECD). Governance of innovation systems, v. 1. Paris: OECD, 2005.

PACHECO, E. R. M. Mapeamento do Fomento à Inovação Tecnológica No Brasil. Rio de Janeiro: CEFET/RJ, 2010.

PUGA, F. P. Sistema Financeiro Brasileiro: Reestruturação Recente, Comparações Internacionais e vulnerabilidade à Crise Cambial. Textos para Discussão, Brasília; BNDES, n. 68, março, 1999.

RAPINI, M. Sistemas Financeiros e o Financiamento a Inovação: Algumas Reflexões para o Brasil. Texto para Discussão. Belo Horizonte: UFMG/Cedeplar, n. 367, 2009.

SALERNO E KUBOTA. Políticas de Incentivo à Inovação Tecnológica no Brasil. Brasília: IPEA, 2008. p. 13-33.

SCHUMPETER, J. A. Capitalismo, Socialismo e Democracia. Rio de Janeiro: Ed. Fundo de Cultura, 1961.

Processo de Destruição Criativa. In: Capitalismo, Socialismo e Democracia. Rio de Janeiro: Zahar, 1984.

Teoria do desenvolvimento econômico. São Paulo: Abril Cultural, 1982.

SMITH, K. Economic Infrastructures and Innovation Systems. In: EDQUIST, C. (Ed.). Systems of Innovation. Technologies, Institutions and Organizations. London: Routledge, 1997.

TIDD, Joe; BESSANT, John; PAVITT, Keith. Gestão da Inovação. Porto Alegre: Bookman, 2008.

VIOTTI, E. B.; BAESSA, A. R.; KOELLER, P. Perfil da Inovação na Indústria Brasileira: Uma comparação Internacional. Brasília: IPEA, 2005. 


\section{Sobre os autores}

\section{Rafaele Paz Comin}

E-mail: rafaelecomin@gmail.com

Graduada em Administração. MBA Executivo em Gestão de Projetos. Mestranda em Propriedade Intelectual e Transferência de Tecnologia para a Inovação.

Endereço profissional: SENAI DR BA

\section{Marcelo Cezar Carvalho Borges}

E-mail: mccborges@gmail.com

Graduado em Ciência da Computação pela Universidade Estadual de Santa Cruz (2003). Pos-Graduado em Sistema de Informação e MBA Executivo em Gestão de Projetos. Mestrando no curso de mestrado profissional em propriedade intelectual e transferência de tecnologia para inovação.

Endereço Profissional: DATEN Tecnologia

\section{Marilís Pereira Moura}

E-mail: maryisa.lima@gmail.com

Graduada em administração de empresas pela Universidade Federal do Mato Grosso do Sul campus Três Lagoas (UFMS/CPTL). Pós-graduanda em Propriedade Intelectual e Transferência de Tecnologia para Inovação (PROFNIT-UESC).

Endereço Profissional: Estudante

\section{Silvio Luis Comin}

E-mail:comin@daten.com.br

Graduado em Contabilidade. Mestrando em Propriedade Intelectual e Transferência de Tecnologia para a Inovação. Diretor Industrial da Daten Tecnologia. Presidente do SINEC - Sindicato das Indústrias de Aparelhos Elétricos, Eletrônicos, Computadores, Informática e Similares dos Municípios de Ilhéus e Itabuna, do Estado da Bahia e também Presidente da ASSIPI - Associação das Indústrias do Polo de Informática de Ilhéus, Ba. Sócio Diretor da Comin Consultoria.

Endereço Profissional: Daten Tecnologia

\section{Gesil Sampaio Amarante Segundo}

E-mail: gsamarante@uesc.br

Graduado em Física - Bacharelado pela Universidade Federal do Rio de Janeiro (1993). Mestre em Física pela Universidade de São Paulo (1996). Doutor em Física pela Universidade de São Paulo (2000). Doutor em Física de Plasmas pela USP, Professor Titular da Universidade Estadual de Santa Cruz (UESC), Vice-Coordenador do NIT-UESC, Presidente do Parque Científico e Tecnológico do Sul da Bahia e Diretor Técnico do FORTEC Endereço Profissional: Universidade Estadual de Santa Cruz, Campus Soane Nazaré de Andrade km 16 Rodovia Jorge Amado CEP 45662-900, Ilhéus - BA

\section{Marina Oliveira Lucas Tavares}

E-mail: marinalucastavares@gmail.com

Graduada em Comunicação Social - Radio e Televisão pela Universidade Estadual de Santa Cruz (2004). Especialista em Marketing Universidade Estácio de Sá/RJ. MBA em Gestão de Recursos Humanos pela Universidade Veiga de Almeida/RJ.

Endereço profissional: Editus - Editora da Universidade Estadual de Santa Cruz - UESC 